\title{
Concessão de crédito para empresas com divergência entre a contabilidade fiscal e societária no Brasil
}

\begin{abstract}
Este trabalho reflete o estudo que foi desenvolvido para tentar solucionar um problema real. Em muitas empresas do setor de construção, há uma grande divergência entre a contabilidade societária e a contabilidade fiscal, isto porque o reconhecimento das receitas ocorre em momentos diferentes, gerando relatórios distintos. Nesta situação, é possível que, enquanto a contabilidade societária apresente lucro, a fiscal apresente prejuízo, por reconhecer uma receita menor que os custos incorridos no período. Esta situação se torna um problema quando a companhia precisa obter crédito nas instituições financeiras, e estas, ao verificarem a disparidade entre a o resultado fiscal e societário, adotam uma posição prudential conservadora e, considerando o resultado fiscal desfavorável, negam o crédito. A pesquisa desenvolvida foi exploratória e o método qualitativo. Foram realizadas oito entrevistas em profundidade com gestores de crédito de grandes corporações financeiras, escolhidas por conveniência, devido à dificuldade de acesso a esses profissionais. A técnica adotada para o tratamento dos dados foi a análise de conteúdo, realizada com o apoio do software NVIVO. Após a análise do material das entrevistas, que refletiu a opinião dos gestores de crédito, foi observada a necessidade de aperfeiçoamento do modelo de análise de crédito para as empresas classificadas no segmento Middle Market. A principal contribuição desta pesquisa, para melhoria do modelo geral de análise de crédito, foi a introdução, na fase de análise financeira, de um Bridge Report, relatório que tem a finalidade de demonstrar a composição e equalização das diferenças entre a contabilidade societária e a fiscal, permitindo, assim, ao Gestor de Crédito tomar uma decisão consciente sem o viés inicial.
\end{abstract}

Palavras-chave: Contabilidade Societária; Contabilidade Fiscal; Análise de Crédito; Risco de Crédito; Bridge Report.

\section{Concession of credit for companies with divergence between tax and corporate accounting in Brazil}

\begin{abstract}
This work reflects the study that was developed to try to solve a real problem. In many companies in the construction industry, there is a great divergence between corporate accounting and fiscal accounting, because revenue recognition takes place at different times, generating different reports. In this situation, it is possible that, as long as the corporate accounting presents a profit, the taxpayer presents a loss, since it recognizes a lower income than the costs incurred in the period. This situation becomes a problem when the company needs to obtain credit from financial institutions, and these, when verifying the disparity between the fiscal and corporate results, adopt a conservative prudential position and, considering the unfavorable fiscal result, deny the credit. The research developed was exploratory and the qualitative method. Eight in-depth interviews were conducted with credit managers from large financial corporations, chosen for convenience, due to the difficulty of access to these professionals. The technique adopted for the data treatment was content analysis, performed with the support of NVIVO software. After analyzing the interview material, which reflected the opinion of the credit managers, it was observed the need to improve the credit analysis model for the companies classified in the Middle Market segment. The main contribution of this research, to improve the general credit analysis model, was the introduction, in the financial analysis phase, of a Bridge Report, a report that aims to demonstrate the composition and equalization of the differences between corporate accounting and Thereby allowing the Credit Manager to make a conscious decision without the initial bias.
\end{abstract}

Keywords: Corporate Accounting; Tax Accounting; Credit Analysis; Credit Risk; Bridge Report.

Topic: Finanças e Contabilidade

Reviewed anonymously in the process of blind peer.

Tiago de Vasconcelos

Universidade Presbiteriana Mackenzie, Brasil

http://lattes.cnpq.br/

tiagodevasconcelos@yahoo.com.br

Luiz Carlos Jacob Perera

Universidade Presbiteriana Mackenzie, Brasil

http://lattes.cnpq.br/3386375141622007

iperera@terra.com.br

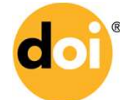

DOI: 10.6008/SPC2179-684X.2016.001.0009
Received: 07/05/2015

Approved: 14/11/2015 


\section{INTRODUÇÃO}

A promulgação da Lei 11.638/07 trouxe uma série de alterações em relação às práticas contábeis no Brasil, a fim de uniformizar as demonstrações contábeis brasileiras com as normas internacionais de contabilidade, conhecidas como International Financial Reporting Standards (IFRS), amplamente aplicadas em países mais desenvolvidos.

Tais mudanças buscaram melhorar a transparência, a compreensibilidade, a relevância, a uniformidade e a qualidade das informações contábeis para os usuários que utilizam as demonstrações financeiras para análises e tomadas de decisão (ANTUNES et al., 2012).

Para perpetrar a convergência entre as normas contábeis brasileiras e as IFRS, o Conselho Federal de Contabilidade (CFC), por meio da Resolução 1.055/05, criou o Comitê de Procedimentos Contábeis, cuja principal função é emitir pronunciamentos técnicos acerca dos procedimentos de contabilidade que devem ser adotados pelas organizações, com base nas normas internacionais que são publicadas e atualizadas pela International Accounting Standard Board (IASB), a entidade internacional responsável pelas IFRS (SILVA, 2013).

Apesar dos esforços para a convergência das normas contábeis em esfera global, ainda existe muita discussão acerca do modo de aplicação de algumas normas IFRS. Além disto, há muita dificuldade nesse processo, pois cada país tem sua legislação específica e suas particularidades fiscais e jurídicas, além da própria cultura.

Todavia, não há o alinhamento completo entre as normas explícitas nos pronunciamentos contábeis e a legislação tributária brasileira, incorrendo em desajustes entre a contabilidade societária e fiscal. Isto ocorre porque os propósitos da regulação contábil e da fiscal são distintos, resultando em diferenças entre os dois resultados (FORMIGONI; ANTUNES; PAULO, 2009).

Um exemplo claro disso é o que ocorre nas entidades que prestam serviço de construção, que possuem projetos com um ciclo operacional longo. O problema está no momento de reconhecimento da receita, uma vez que o CPC 17, correlato ao IAS 11, que regula a contabilização dos contratos de construção, permite formas de reconhecimento de receita distintas do que é exigido na legislação tributária. Como consequência, a contabilidade societária reconhece a receita em período diferente da contabilidade fiscal, afetando diretamente o resultado do exercício e, consequentemente, a apuração do imposto de renda e da contribuição social. Além disto, gera discrepância nas análises dos índices financeiros das demonstrações contábeis, quando da comparação entre os relatórios financeiros societários e fiscais observados pelos usuários externos.

Para exemplificar o tema deste artigo, bem como ilustrar aos respondentes o assunto a ser abordado na pesquisa qualitativa, foi utilizada como base as operações da Monorail Engineering, empresa com o nome fictício, com sede na Índia, operante nos segmentos de transporte marítimo, transportes urbanos e Oil \& Gas, que estabeleceu uma filial no Brasil em 2011. Esta empresa foi responsável pela execução do projeto de 
construção da Linha Roxa do Metrô de São Paulo (projeto fictício), juntamente com outras empresas que são responsáveis pela parte de construção civil, compreendendo o consórcio envolvido no projeto.

O contrato estabelecido com o Metrô de São Paulo tinha o preço fixo e determinava as datas dos pagamentos parciais com base na medição do projeto, ou seja, de acordo com a conclusão de etapas do projeto, pré-estabelecidas no contrato. Quando da emissão da Nota Fiscal de Serviço ou de mercadorias pela Monorail Brasil e o posterior envio ao Metrô de São Paulo, o pagamento era efetivado, e em consequência havia a respectiva tributação dos impostos por parte do fisco.

Quanto ao reconhecimento das despesas e receitas relativas ao contrato de construção, a contabilização era feita seguindo os procedimentos definidos pelo CPC 17 (correlato ao IAS 11) através de uma provisão de receita, uma vez que todas as condições estabelecidas eram atendidas.

Em países que seguem o accrual basis of accounting definidos pelo IAS 1, é possível realizar uma provisão de receita sem ocorrer a tributação de impostos diretos e indiretos, entretanto, no Brasil, o procedimento de provisão de receita não existe na contabilidade fiscal, principalmente Imposto de Serviços de qualquer natureza, ainda que pela Instrução Normativa no 21, de 13/03/1979, seja permitido computar o PIS, COFINS e IRPJ para a apuração de resultado, no caso de avaliação do andamento da obra com base nos custos incorridos.

O CPC 17 define que, se a conclusão do contrato puder ser estimada com confiabilidade, os custos, despesas e receitas atinentes ao contrato podem ser reconhecidos com base no estágio de execução (stage of completion) da atividade contratual. O referido pronunciamento ainda afirma que: "[...] os pagamentos parcelados e os adiantamentos recebidos dos clientes não refletem, necessariamente, o trabalho executado e não devem servir de parâmetro para mensuração da receita" (CPC 17, 2012, p. 9). Assim, as empresas apuraram seu resultado com base no critério que demonstre mais acuradamente a realidade da execução da obra.

Para a Monorail Engeneering do Brasil, o método que melhor mensura o trabalho executado é a proporcionalidade dos custos incorridos, vis-à-vis ao custo total da obra, além de ser um requerimento interno da matriz, porém, a forma de medição preestabelecida no contrato é a evolução física do trabalho contratado. A proporcionalidade da evolução física da obra difere dos gastos incorridos para a sua execução, que são superiores.

Assim, enquanto a contabilidade societária apresentava lucro, a contabilidade fiscal apresentava prejuízo, pois as receitas são reconhecidas de acordo com a emissão das notas fiscais de prestação de serviços da empresa, que formam a receita bruta e servem de base para o cálculo dos impostos incidentes sobre o faturamento da empresa - Imposto sobre Serviços (ISS), Programa de Integração Social (PIS) e Contribuição para o Financiamento da Seguridade Social (COFINS). Essa empresa está enquadrada no Lucro Real, então a apuração do Imposto de Renda e da Contribuição Social é baseada no lucro fiscal.

A diferença entre a contabilidade fiscal e societária é recorrente porque os propósitos são distintos. São classificadas em dois tipos: diferenças permanentes e temporárias. As diferenças permanentes ocorrem quando certas receitas e despesas são reconhecidas contabilmente, mas não possuem efeito tributário; e as 
diferenças temporárias ocorrem quando as receitas são reconhecidas em ambas, mas em momentos distintos, sendo esse o caso das empresas que firmam contratos de longo prazo, como essa companhia em estudo (FORMIGONI; ANTUNES; PAULO, 2009).

No Brasil, a situação de Provisão de Receita não existe. Quando se credita o Demonstrativo de Resultado do Exercício (DRE), automaticamente presume-se que a receita é realizada e por consequência ocorre a tributação dos impostos nas esferas da União, Estados e Municípios.

Devido às diferenças de reconhecimento de receita entre a contabilização fiscal e a societária, a Monorail Engineering Brasil possuía dois relatórios financeiros: o societário e o fiscal. E, quando comparados, percebia-se posições diferentes e até mesmo conflitantes, principalmente, no aspecto de reconhecimento de receita, já que para o Fisco brasileiro a emissão da nota fiscal é o meio utilizado para se calcular e recolher os impostos, e, de acordo com CPC 17, a receita pode ser calculada pela confrontação dos custos e despesas na proporção da Receita total do projeto.

Entre outras situações, essas divergências criam problemas para a aquisição de empréstimos em decorrência dos diferentes índices de liquidez e rentabilidade que eram gerados pelos relatórios financeiros da contabilidade societária e da contabilidade fiscal. Durante as posteriores análises, os analistas de crédito dos bancos questionavam a grande diferença dos relatórios entre a contabilidade societária e a contabilidade fiscal.

Por meio deste estudo, pretendeu-se trazer à discussão as possíveis melhorias de análise no modelo de concessão de crédito por parte das instituições financeiras que analisam crédito para empresas do segmento Middle Market, e que apresentam divergências nos relatórios da contabilidade societária e na contabilidade fiscal, para uma posterior sugestão de modelo de análise de crédito.

A pesquisa foi desenvolvida com profissionais de instituições financeiras que concedem crédito para empresas que possuem disparidades entre a contabilidade societária regidas pela IFRS/ CPC e a contabilidade fiscal, buscando diagnosticar pontos de melhoria no modelo de análise de concessão de crédito visando identificar o que poderia ser melhorado em um modelo de análise de crédito para uma empresa do segmento Middle Market.

\section{REVISÃO TEÓRICA}

Inicialmente será delineado o escopo dos relatórios de análise deste projeto, sendo que a abordagem será dos relatórios da Contabilidade Societária e da Contabilidade Fiscal com finalidades de uso externo, e não os relatórios da Contabilidade Gerencial cujo objetivo é uso interno da empresa para a tomada de decisões, e ocasionalmente algum suporte à Contabilidade Societária.

O Brasil teve, durante muitos anos, dois documentos sobre a estrutura conceitual da contabilidade, sendo um deles elaborado em 1986 pelo Fundação Instituto Brasileiro de Pesquisas Contábeis, Atuariais e Financeiras (Fipecafi), e outro emitido pelo Conselho Federal de Contabilidade (CFC), pela Resolução no 750, em 1993, Princípios Fundamentais de Contabilidade, seguida de um apêndice introduzido pela Resolução CFC no 774/94 e pela Resolução CFC no 785/95, essa sobre as características da Informação Contábil. A partir da 
Lei no 11.638/07 e a decisão pela convergência da contabilidade brasileira às Normas Internacionais de Contabilidade emitidas pelo IASB, O CPC adotou integralmente o documento daquele órgão denominado informalmente de CPC 00, prezando, principalmente, uma maior aderência ao conceito da primazia da essência sobre a forma, ponto esse fundamental defendido pelo IASB (IUDíCIBUS et al., 2010).

O objetivo do relatório contábil-financeiro de propósito geral é fornecer informações contábilfinanceiras acerca da entidade que reporta essa informação, reporting entity, que sejam úteis a investidores existentes e em potencial, a credores por empréstimos e a outros credores, quando da tomada decisão ligada ao fornecimento de recursos para a entidade. Essas decisões envolvem comprar, vender ou manter participações em instrumentos patrimoniais e em instrumentos de dívida, e oferecer ou disponibilizar empréstimos ou outras formas de crédito.

As demonstrações contábeis são preparadas e apresentadas para usuários externos em geral, tendo em vista suas finalidades distintas e necessidades diversas. Governos, órgãos reguladores ou autoridades fiscais, por exemplo, podem especificamente determinar exigências para atender a seus próprios fins. Essas exigências, no entanto, não devem afetar as demonstrações contábeis preparadas segundo essa estrutura conceitual.

O International Accounting Standards 11 (IAS 11) é aplicado no tratamento contábil das receitas e custos associados a contratos de construção na data em que o contrato é celebrado e a data futura em que a atividade será concluída em períodos contábeis diferentes. Dessa forma, a sua mensuração é a alocação de custos do contrato aos períodos em que o trabalho de construção será realizado.

A proporção de reconhecimento de receita é calculada com base no valor inicial de receitas pactuado no contrato e em suas alterações, desde que a receita seja mensurada de forma confiável. Os custos do contrato compreenderão os custos diretamente relacionados ao contrato, que poderão serem alocados ao contrato e cobrados do cliente de acordo com as normas do contrato.

O CPC 17 é correlato à norma Internacionais de contabilidade - IAS 11.

Um sistema tributário compreende o conjunto de leis e normas gerais da legislação tributária que define os tributos, seus respectivos fatos geradores, bases de cálculo, contribuintes, determinando quais são as obrigações tributárias, como devem ser os lançamentos e, ainda quando se dá a prescrição e decadência (GALLO, 2007, p. 114).

De acordo com Perera (2013, p. 69), “[...] os bancos dão crédito às pessoas baseados em escores ou no risco que cada indivíduo representa. Indivíduos com histórico de pagamentos de empréstimos satisfatórios continuam a tomar novos empréstimos".

Qual o significado de crédito? Entre as diversas definições, seguem algumas para a continuidade deste estudo.

Para a avaliação de risco de crédito de pessoas jurídicas que elaboram os demonstrativos econômico-financeiros básicos, o analista de crédito deverá formar um dossiê contendo os Balanços Patrimoniais, as Demonstrações de Resultado dos Exercícios, o Quadro de Mutações do patrimônio Líquido e as Demonstrações das Origens e Aplicações de Recursos. É usual o credor solicitar os demonstrativos referentes aos três últimos exercícios e, em situações em que o crédito esteja sendo avaliado em mês distante da data de fechamento do último exercício, pedir adicionalmente um balancete recente. Algumas empresas, constituídas sob a forma de sociedades por quotas de responsabilidade limitada, nem 
sempre elaboram todos os demonstrativos, oferecendo apenas os Balanços, as Demonstrações de Resultados e o Balancete de Verificação (SECURATO, 2007, p. 59).

Quadro 1: Resumo do conceito de crédito.

\begin{tabular}{|l|l|}
\hline Autor & Definição \\
\hline BLATT, 2000 & $\begin{array}{l}\text { "Crédito é 'crer' e crer é 'confiar'. A palavra crédito } \\
\text { tem sua origem no latim credere, que significa: crer, } \\
\text { confiar, acreditar, ou ainda, do substantivo creditum, o } \\
\text { qual literalmente significa 'confiança”. }\end{array}$ \\
\hline HOUAISS, 2012 & $\begin{array}{l}\text { O vocábulo crédito deriva do latim creditum, que, em } \\
\text { essência, significa crença, confiança, empréstimo }\end{array}$ \\
\hline SANTOS, 2009 & $\begin{array}{l}\text { "Crédito, em finanças, é definido como a modalidade de } \\
\text { financiamento destinada a possibilitar a realização de } \\
\text { transações comerciais entre empresas e seus clientes". }\end{array}$ \\
\hline SILVA, 2003 & $\begin{array}{l}\text { [...] entrega de um valor presente mediante uma } \\
\text { promessa de pagamento. }\end{array}$ \\
\hline PERERA, 2013 & $\begin{array}{l}\text { A palavra crédito vem do latim credo e significa eu } \\
\text { acredito ou eu confio. A confiança básica para qualquer } \\
\text { transação de crédito não é unilateral, isto é, tanto o } \\
\text { vendedor confia na boa fé e na capacidade de } \\
\text { pagamento do comprador, dentro de um determinado } \\
\text { prazo, quanto o comprador confia no valor dos bens ou } \\
\text { dos serviços que está adquirindo. }\end{array}$ \\
\hline
\end{tabular}

Para Shimko (1999), o modelo de crédito é uma arte que avança rapidamente, com uma grande quantidade de fatores e de constantes melhorias, de maneira que a seleção do modelo de risco de crédito apropriado é um importante aspecto para o gerenciamento do risco de crédito. Um modelo de risco de crédito impróprio trará erros e um aumento de riscos para a operação, e falhas no gerenciamento do risco concedido, o qual impactará a instituição financeira em termos de ganhos ou perdas, liquidez, volatilidade de mercado e riscos operacionais.

\section{METODOLOGIA}

\section{Tipologia de Estudo e Método de Pesquisa}

Segundo Beuren (2009, p. 80):

A caracterização do estudo como pesquisa exploratória normalmente ocorre quando há pouco conhecimento sobre a temática a ser abordada. Por meio do estudo exploratório, busca-se conhecer com maior profundidade o assunto, de modo a torná-lo mais claro ou construir questões importantes para a condução da pesquisa.

Tendo como base a investigação dos fatores mencionados, este estudo se caracterizou como de natureza exploratória e, para atender aos objetivos geral e específico, utilizou-se o método qualitativo.

A Pesquisa qualitativa é um processo de questionamento e entendimento baseado na metodologia distinta de tradições que explora os problemas sociais e humanos. 0 pesquisador constrói um complexo, uma figura holística, analisa palavras, reporta o ponto de vista de informantes e conduz o estudo de modo natural (CRESWELL, 1998, p. 15, tradução nossa).

Segundo Beuren (2009), a pesquisa qualitativa proporciona análises mais profundas em relação ao fato que está sendo estudado. Para a coleta de dados, foram realizadas entrevistas em uma amostra por 
conveniência, com gestores de crédito de instituições financeiras, em que foi discutido o exemplo prático da empresa Monorail Engeneering, apenas para balizar e identificar os atuais procedimentos utilizados no modelo de análise de crédito para empresas que possuem divergências nos relatórios financeiros da contabilidade societária e da contabilidade fiscal, cuja técnica adotada para o tratamento dos dados foi a análise de conteúdo.

\section{População}

A população deste seria a dos gestores de crédito de bancos, sendo que, por questões de confidencialidade, os nomes dos profissionais e das instituições foram preservados. A seleção dos respondentes foi por julgamento, sendo que os profissionais selecionados foram os gestores de crédito de Middle Marketing em número de 8 (oito) respondentes. Dos oito profissionais de crédito de instituições financeiras entrevistados, três foram por meio da rede de contatos pessoais do pesquisador e cinco foram contatados pela rede de relacionamento Linkedln.

\section{Procedimentos de Coleta de Dados}

Para este trabalho, por sua característica qualitativa, foram realizadas entrevistas em profundidade com perguntas abertas e fechadas, cujo instrumento de coleta de dados foi composto por um roteiro semiestruturado previamente elaborado.

Foi enviado um convite formal para os entrevistados, um roteiro de entrevista e um termo de confidencialidade, a fim de garantir a não divulgação do nome do participante e da instituição financeira. Esses documentos podem ser verificados no Apêndice deste projeto. Apresentou-se um caso verídico de uma empresa, com o nome fictício, para ilustrar o contexto da pesquisa, e, após, foi aplicado um questionário com a finalidade de delimitar o escopo abordado nas entrevistas e estudo de caso com os gestores de crédito das instituições financeiras/ bancos.

Foi realizado um pré-teste do roteiro de entrevista com um profissional da área de crédito, o qual mantém conhecimento da área e dos detalhes específicos do objeto deste estudo. Após, foram realizados ajustes no roteiro perfazendo a última versão dele para ser aplicado na pesquisa de campo.

$O$ roteiro de entrevistas foi elaborado com base na seguinte estrutura: (a) perguntas para a caracterização da empresa; (b) perguntas para caracterizar o profissional respondente; (c) dez perguntas abertas e fechadas para atender aos objetivos desta pesquisa, visando a obtenção dos resultados desejados.

Os contatos da rede de relacionamentos foram realizados primeiramente por e-mail e, em seguida, por telefone, correspondendo a um total de sete pessoas, sendo que apenas três retornaram e se propuseram a um encontro para que fosse realizada a entrevista. Com a finalidade de obter um maior número de respondentes para este estudo, utilizou-se a rede de relacionamento Linkedln, foram selecionados, adicionados e convidados profissionais da área de análise de crédito de diversas instituições financeiras. Em um total de 20 profissionais, cinco aceitaram o convite para participar deste estudo. 
Primeiramente, os profissionais mostraram-se receosos pela exposição pessoal e da instituição financeira que este projeto de pesquisa poderia proporcionar. Diante disso, foi enviado por e-mail um termo de confidencialidade juntamente com um convite oficial explicando o projeto em questão, bem como a segurança da não exposição e confidencialidade do nome do respondente e da instituição financeira; também em sua totalidade apresentaram insegurança quanto ao que seria abordado durante a entrevista. Dessa maneira, foi enviado um roteiro de entrevista a fim de tranquilizá-los e balizar o que seria conversado durante a entrevista.

As entrevistas foram realizadas no mês de outubro de 2014, e no encontro presencial, tanto o convite formal, o roteiro de entrevista e o termo de confidencialidade foram entregues fisicamente ao respondente antes do início das entrevistas, deixando-os à vontade para conversarem sobre o tema da entrevista.

\section{Procedimentos de Tratamento dos Dados}

Foram adotados os seguintes procedimentos para a análise de dados: entre as técnicas de análise de dados qualitativos, foi utilizada a análise de conteúdo com um modelo aberto. A análise de conteúdo foi realizada em 3 etapas, sendo a primeira a etapa de pré análise, sendo seguida pela etapa de exploração do material, e, por último, a etapa do tratamento dos resultados, momento esse em que ocorre a inferência e a interpretação.

Durante a etapa prévia de análise, foram organizadas as ideias e materiais, de maneira a estruturar os indicadores que irão fundamentar a interpretação final, buscando a exaustividade em levar em consideração todos os elementos, sem qualquer omissão; a representatividade de forma que a amostra utilizada representa o universo pesquisado; a homogeneidade da pesquisa de um mesmo tema ser obtida por uma mesma técnica e por indivíduos semelhantes; e a pertinência em que os documentos pesquisados contribuem para o alcance do objetivo da pesquisa.

A etapa de exploração do material consistiu nas operações de codificação, decomposição ou enumeração de acordo com os critérios previamente definidos, buscando, por meio dos dados brutos, uma representação do conteúdo das escolhas das unidades, das regras de contagem e das escolhas das categorias. Após terem sido estabelecidas as categorias, deu-se continuidade com a análise de conteúdo, com as inferências e interpretações.

As execuções das entrevistas foram executadas pelo próprio pesquisador, anotadas e gravadas em meio digital na forma de áudio MP3 mediante a autorização do entrevistado. Em seguida, as entrevistas gravadas foram transferidas para um ultrabook, em que todas as atividades de análise serão realizadas, após foram transcritas em Word e foram transferidas para a análise e avaliação no software NVIVO versão 8. Foram estabelecidas as subcategorias, agrupadas em categorias de análise que foram estruturadas durante as etapas de análise.

\section{RESULTADOS E DISCUSSÃO}


Conforme Quadro 2, pode-se verificar a caracterização dos oito respondentes quanto aos cargos ocupados nos respectivos bancos, sua área de formação acadêmica e o respectivo tempo na instituição financeira e no mercado como um todo.

Quadro 2: Caracterização dos entrevistados.

\begin{tabular}{|c|c|c|c|c|c|}
\hline Entrevista & Cargo ocupado & Graduação & Pós Graduação & $\begin{array}{l}\text { Tempo na } \\
\text { Instituição }\end{array}$ & $\begin{array}{l}\text { Tempo no } \\
\text { Mercado }\end{array}$ \\
\hline RESP 1 & Gerente & Administração & Latus Sensus/ Controladoria & 4 anos & 24 anos \\
\hline RESP 2 & Analista Sênior & Administração & Latus Sensus/MBA Finanças & 3 anos & 8 anos \\
\hline RESP 3 & Superitendente & Economia & Latus Sensus/MBA em Gestão & 12 anos & 15 anos \\
\hline RESP 4 & Analista Sênior & Administração & - & 2 anos & 6 anos \\
\hline RESP 5 & Gerente & Administração & Latus Sensus/MBA Finanças & 6 anos & 23 anos \\
\hline RESP 6 & Gerente & Economia & Latus Sensus/Finanças & 2 anos & 24 anos \\
\hline RESP 7 & Gerente & Administração & Latus Sensus/Gestão Empresarial & 9 anos & 15 anos \\
\hline RESP 8 & Gerente & Economia & Latus Sensus/Finanças & 20 anos & 20 anos \\
\hline
\end{tabular}

Como primeira etapa da análise de conteúdo, foram identificadas as palavras-chave por meio de uma consulta no software NVIVO. As informações geradas auxiliaram no processo de avaliação e análise dos principais pontos abordados pelos entrevistados.

Em uma segunda etapa, houve a formação das unidades de significado, todas as entrevistas foram transcritas e transferidas para o software NVIVO, possibilitando a criação de nós ou subcategorias, e a alocação dos trechos analisados para cada nó já previamente cadastrado. Foram estipulados 31 subcategorias/nós.

Na terceira etapa, houve a categorização, buscando a classificação de elementos a partir da análise das informações e agrupamento dos conceitos.

A quarta etapa da análise de conteúdo se refere à análise de resultados, momento em que as 31 subcategorias foram agrupadas em 4 categorias.

\section{CAT 1 - Análise de Crédito}

Nesta categoria, foram abordados os conceitos de segmentação de mercado por faturamento, nível de informalidade de processos nas empresas, o modelo, as ferramentas no processo de análise de crédito e o perfil do profissional de crédito.

\section{Segmentação de mercado pelo faturamento}

Os bancos de maneira geral se organizam em quatro principais segmentos, sendo eles: Small Market, Middle Market, Corporate e Large Corporate, podendo mudar a nomenclatura de banco para banco, sendo que o principal fator para essa divisão é o faturamento anual que a empresa possui.

O Small Market, também chamado por algumas instituições financeiras como Pequenas e Médias Empresas (PME), são as empresas que apresentam um faturamento de até $\mathrm{R} \$ \mathbf{5 0}$ milhões por ano. O Middle Market é a segmentação bancária que apresenta a principal necessidade de mudança no modelo de análise de crédito dos bancos. O faturamento das empresas para a segmentação dos bancos varia de instituição para instituição, possuindo um intervalo no faturamento anual de $\mathrm{R} \$ 50$ milhões a $\mathrm{R} \$ \mathbf{6 0 0}$ milhões anuais. São 
empresas que possuem características tanto da segmentação Small quanto do Corporate, acentuando-se tais características da empresa de acordo com o faturamento. O segmento Corporate enquadra as empresas com o faturamento anual a partir de $\mathrm{R} \$ 600$ milhões até $\mathrm{R} \$ 2$ bilhões. E, por último, no segmento Large Corporate, são classificadas as empresas que apresentam um faturamento anual acima de $R \$ \frac{2}{2}$ bilhões.

\section{Segmentos e suas características}

O segmento Small Market enquadra empresas de pequeno porte, geralmente com características de empresas familiares que não possuem uma política interna estruturada, nem processos definidos e governança corporativa.

As empresas do Middle Market apresentam tanto características do Small Market quanto do Corporate. Dessa maneira, encontram-se empresas tanto com características de informalidade quanto com características de formalidade de política interna, processos e governança corporativa e compliance bem estabelecidos, dependendo da polarização do faturamento que a empresa apresente.

Possuem uma estruturação mais formal que empresas do Small Market e, à medida que seu faturamento aumenta, tendem a processos maduros e aplicados similares ao da segmentação Corporate. De acordo com a opção da entidade jurídica e faturamento anual apresentado, quanto mais próximo o faturamento das empresas do segmento Corporate, são obrigadas a elaborar os relatórios societários.

Tanto as empresas do segmento Corporate quanto do Large Corporate possuem um grande nível de formalidade, com processos, política interna e governança corporativa bem definida.

\section{Modelo e ferramentas de análise de crédito}

Quanto ao modelo de análise de crédito, pode-se verificar que geralmente o processo é engessado, embasado por manuais e sistemas, além de haver a tendência da diminuição da interferência do analista de crédito, embora em algumas instituições financeiras ainda exista.

As instituições financeiras possuem índices internos para a análise. Há o cruzamento de informações internas do cliente e uma grande informalidade quanto à pesquisa em outras instituições bancárias pela rede de contato pessoal do analista de crédito com analistas de outras instituições financeiras, ocasionando uma ilegalidade pela quebra do sigilo bancário, porém esse procedimento não é institucional e oficial.

Para o segmento Small Market, análise de crédito é mais mecânica, sendo que há sistemas no qual um valor de crédito pré-aprovado já é disponibilizado. Essa automação é decorrência do valor do crédito solicitado, histórico, tipo de demanda e alto número de solicitações de crédito. No segmento Middle Market, dependendo do enquadramento do faturamento da empresa, há a tendência de as demandas serem mais personalizadas, necessitando uma interferência maior do analista de crédito. Para os segmentos Corporate e Large Corporate, as demandas de crédito possuem análises mais detalhadas. Geralmente, os valores de crédito solicitados são maiores e destinados a projetos com um nível de complexidade mais elevado.

Além da utilização de ferramentas como a SERASA, e, em casos mais específicos de informações de agências de risco, os bancos que possuem uma boa base de dados tornam o processo de análise mais fácil, 
pois possuem mais informações para comparação e análise, como, por exemplo, informações de concorrentes, fornecedores e parceiros da empresa tomadora. Já os bancos menores são mais vulneráveis a isso, havendo, inclusive, a tendência de conceder crédito para empresas que já sejam tomadoras de banco maiores, pois concluem que o risco da empresa foi bem aceito pelo mercado.

A demanda de análise é grande em comparação ao número de profissionais de crédito disponíveis, ocorrendo pouco tempo de análise, pouco aprofundamento em cada caso de solicitação de crédito, fatores que, aliados ao desconhecimento e falta de treinamento dos profissionais, podem resultar em recusas e aprovações de crédito equivocadas.

O Quadro 3 demonstra as principais características da segmentação bancária em decorrência do porte da empresa atendida. Pode-se observar que, no segmento Middle Market, em decorrência de possuir um grande intervalo de faturamento, são encontradas empresas que possuem características que variam do segmento Small Market ao segmento Corporate.

Em decorrência dessa polarização do Middle Market, no Quadro 3, foi definido graficamente o intervalo Sim/Não para os quesitos de: informalidade, utilização de relatórios da contabilidade fiscal, utilização de relatórios da contabilidade societária e se as empresas são auditadas.

Para a análise de concessão de crédito, os analistas levam em consideração principalmente o segmento da empresa, a sazonalidade do mercado, a estrutura gerencial, a experiência dos sócios, o caráter, se a gerência é profissional, se a estrutura é familiar, se existe plano de sucessão, a finalidade para que o crédito é concedido, tudo sempre suportado por uma visita em que o analista tem a possibilidade de constatar se o que foi discutido condiz com a realidade.

Quadro 3: Segmentação bancária.

\begin{tabular}{|l|c|c|c|c|}
\hline & Small Market & Middle Market & Corporate & Large Corporate \\
\hline $\begin{array}{l}\text { Empresas com faturamento } \\
\text { anual }\end{array}$ & até R\$50 Milhões & $\begin{array}{c}\text { de R\$50 milhões } \\
\text { até R\$600 milhões }\end{array}$ & $\begin{array}{c}\text { de R\$600 milhões } \\
\text { até R\$2 Bilhões }\end{array}$ & $\begin{array}{c}\text { Acima de R\$2 } \\
\text { Bilhões }\end{array}$ \\
\hline $\begin{array}{l}\text { As empresas apresentam } \\
\text { Informalidade }\end{array}$ & $\operatorname{Sim}$ & Sim ou Não & Não & Não \\
\hline $\begin{array}{l}\text { Utilização de Relatórios da } \\
\text { contabilidade fiscal }\end{array}$ & Sim & Sim ou Não & Não & Não \\
\hline $\begin{array}{l}\text { Utilização de Relatórios da } \\
\text { contabilidade societária }\end{array}$ & Não & Sim ou Não & Sim & Sim \\
\hline Empresas utilizam o IFRS/CPC & Não & Não & Sim & Sim \\
\hline Empresas são auditadas & Não & Sim ou Não & Sim & Sim \\
\hline
\end{tabular}

\section{Perfil do profissional de crédito}

Quanto ao perfil do profissional de crédito foi verificado que há uma tendência em substituir os profissionais mais experientes por profissionais com um perfil 'Júnior', com pouca experiência e com menor custo em decorrência de pressões orçamentárias, embora isso não seja regra. 
Os novos profissionais possuem uma rápida formação, pouco tempo de maturação, pouco conhecimento de matemática financeira, administração financeira e contabilidade. Os profissionais mais experientes estão se aposentando, ou sendo enquadrados em uma posição mais elevada no mercado, reduzindo a sua competitividade e empregabilidade em detrimento do custo.

As instituições financeiras, visualizando essa mudança da qualidade do profissional da área de crédito, vêm cada vez mais se utilizando recursos tecnológicos e sistêmicos para a análise de crédito, deixado cada vez mais o processo engessado e balizado por sistemas, parametrizando-se informações, fazendo com que o processo seja mais automático, massificado e ágil.

\section{CAT 2 - Contabilidade fiscal}

Quanto à utilização da contabilidade fiscal para a análise de crédito, foi observado que isto depende muito do porte da instituição a ser analisada e o modelo de crédito da instituição financeira.

No segmento Small Market, em decorrência do enquadramento legal das empresas nesse segmento, as empresas não são obrigadas a apresentar Balanço e Demonstrativo de Resultado do Exercício (DRE), elas não possuem uma contabilidade societária estruturada e confiável. Assim, os bancos utilizam os relatórios da contabilidade fiscal, juntamente com a análise da movimentação bancária da Pessoa Jurídica e dos sócios. Para as empresas enquadradas no segmento Middle Market, dependendo da polarização de faturamento que a empresa possua, podem ser solicitados tanto os relatórios fiscais como os societários. Em empresas com faturamentos similares ao segmento Small Market, os relatórios fiscais são utilizados; em empresas com faturamentos mais próximos ao segmento Corporate, os relatórios fiscais não são utilizados. Para empresas nos segmentos Corporate e Large Corporate, os relatórios fiscais não são solicitados, principalmente pelo nível governança, de maturidade e confiabilidade dos relatórios societários.

Algumas instituições financeiras, por possuírem uma vasta base de dados, não utilizam nem os relatórios societários, nem os fiscais para a análise de crédito. Na verdade, utilizam, como principal meio de análise, o seu banco de dados interno.

\section{CAT 3 - Contabilidade societária}

Nesta categoria, foi abordada a utilização dos relatórios societários na análise de crédito e o conhecimento em International Financial Reporting Standard (IFRS) por parte dos analistas de crédito.

\section{Utilização dos relatórios societários}

Para as empresas do segmento Small Market, os relatórios societários não são levados em consideração para a análise de crédito, mesmo porque estas empresas não possuem tal obrigação, e muitas que possuem, tais relatórios não são confiáveis. A contabilidade societária é utilizada principalmente para empresas de segmentadas no Middle Market, Corporate e Large Corporate.

No segmento Middle Market, os relatórios societários somente são utilizados para as empresas que possuem características de processos, governança e compliance ao do segmento Corporate. 
Os relatórios societários somente possuem validade e credibilidade caso a empresa seja auditada por uma Big Four, que são as quatro maiores empresas contábeis especializadas em auditoria e consultoria do mundo, sendo elas a PricewaterhouseCoopers, Deloitte Touche Tohmatsu, Klynveld Peat Marwick Goerdeler (KPMG) e Ernest \& Young (EY).

Caso a empresa não seja auditada, ou caso seja auditada por alguma empresa Non Big Four, os relatórios societários não possuem validade de análise, e o fiscal volta a prevalecer. Há também a análise do projeto, dependendo da finalidade da solicitação do crédito, juntamente com outras ferramentas de análise, como SERASA, percepções da visita-crédito, feeling do analista de crédito e até mesmo informações extraoficiais de relacionamento com outros bancos, incorrendo em quebra do sigilo bancário, apesar de ser procedimento usual e não oficial.

\section{Conhecimento em IFRS/ CPC}

De acordo com as entrevistas de todos respondentes, quanto ao conhecimento em IFRS, foi percebido o pouco ou nenhum conhecimento das normas internacionais por parte dos profissionais de análise de crédito, embora muitos possuam a consciência da necessidade de tal conhecimento.

Os profissionais da área de crédito parecem desconhecer a interpretação, o racional e a base normativa dos números apresentados nos relatórios societários em decorrência do não conhecimento das IFRS. Além disso, levam em consideração os relatórios somente caso a empresa seja auditada por empresas Big Four.

\section{CAT 4 - Risco}

Para as empresas do segmento Small Market, quanto à garantia, o aval dos sócios é mandatório, pois a personalidade jurídica da empresa e a da pessoa física são, muitas vezes, confundidas, sendo o patrimônio dos sócios o principal fator que suporte a maioria das operações de crédito da empresa. Nas empresas do segmento Middle Market mais próximas ao segmento Small Market, o aval ainda é solicitado como garantia, mas por si só não é suficiente para suportar a operação, sendo necessária a utilização de garantias reais. Por outro lado, nas empresas do Middle Market com faturamento e características mais próximas do segmento Corporate, o aval dos sócios não é necessário, devendo apresentar as garantias reais. Para as empresas do segmento Corporate e Large Corporate, geralmente a garantia é o próprio projeto, recebíveis deste projeto, ou até mesmo os ativos da empresa.

Em concordância com Securato (2007), outros fatores também são levados em consideração na mensuração do risco, como a situação econômica e o histórico de crédito da empresa, sócios ou diretores, além daqueles que afetam o setor em que a empresa está inserida e sua posição competitiva em relação aos demais concorrentes.

\section{Extrato geral das entrevistas}


O Quadro 4 demonstra o resumo dos pontos principais das entrevistas realizadas, a disposição foi organizada pela segmentação em que o gestor de crédito atua, sendo que em alguns casos ele atende empresas classificadas tanto no segmento Small e Middle Market, e em outros casos empresas do segmento Middle Market e Corporate. Dessa forma, as empresas do segmento Middle Market, como já foi explicado, podem possuir características tanto do Small quanto do Corporate.

O banco no qual o respondente 8 trabalha é um outlier, pois não utiliza os relatórios societários nem os fiscais, mas sim um pesado e complexo sistema de informação interna e recursos tecnológicos de análise, aliado ao grande banco de dados em decorrência do seu porte bancário e fusões ocorridas em seu negócio no passado, realizando análises dos fornecedores, de clientes, de pagamentos e recebimentos da empresa solicitante de crédito.

Quadro 4: Resumo dos pontos principais.

\begin{tabular}{|c|c|c|c|c|c|c|c|c|c|}
\hline $\begin{array}{l}\text { Segmento de } \\
\text { atuação }\end{array}$ & Respondente & $\begin{array}{l}\text { Utilização de } \\
\text { Relatórios } \\
\text { Societário }\end{array}$ & $\begin{array}{c}\text { Utilização de } \\
\text { Relatórios } \\
\text { Fiscais }\end{array}$ & $\begin{array}{c}\text { Utilização de } \\
\text { Sistema de } \\
\text { Informação } \\
\text { Interno }\end{array}$ & $\begin{array}{c}\text { Utilização de } \\
\text { Sistema de } \\
\text { Infomação } \\
\text { Externo }\end{array}$ & $\begin{array}{c}\text { O Gestor de } \\
\text { Crédito possui } \\
\text { Conhecimento } \\
\text { de IFRS }\end{array}$ & $\begin{array}{l}\text { Utilização do } \\
\text { Feeling para a } \\
\text { análise de } \\
\text { crédito }\end{array}$ & $\begin{array}{l}\text { Como é o } \\
\text { Modelo de } \\
\text { Crédito atual }\end{array}$ & \begin{tabular}{|c|} 
Há a \\
necessidade \\
de mudança \\
no modelo de \\
análise de \\
crédito \\
\end{tabular} \\
\hline Small & RESP 6 & Não & Sim & Sim & Sim & Não & Sim & Estrutuado & Não \\
\hline Small-Middle & RESP 7 & Sim & Sim & Sim & Sim & Não & Sim & Estrutuado & Sim \\
\hline Middle & RESP 2 & Não & Sim & Não & Sim & Não & Sim & Não estruturado & Sim \\
\hline Middle & RESP 3 & Não & Sim & Não & Sim & Não & Sim & Não estruturado & Não \\
\hline Middle & RESP 5 & Sim & Não & Sim & Sim & Não & Sim & Estrutuado & Não \\
\hline Middle-Corporate & RESP 1 & Sim & Não & Sim & Sim & Não & Sim & Estrutuado & Não \\
\hline
\end{tabular}

Dos oito respondentes desta pesquisa, cinco deles acreditam que o modelo de crédito vigente no banco não necessita mudança e apenas três acreditam que o modelo necessita mudança. Por outro lado, foi constatado que nenhum deles possui formação superior em contabilidade e conhecimento em IFRS/ CPC, utilizando-se de outros tipos de informações para a análise de crédito. Como os respondentes não conhecem as IFRS ou CPC, eles não julgam a necessidade de mudança do modelo de crédito atual em decorrência das IFRS.

\section{CONSIDERAÇÕES FINAIS}

Para a elaboração de um novo modelo de análise de crédito para empresas do Middle Market que apresentam divergências entre a contabilidade societária e a contabilidade fiscal, foram estabelecidas algumas premissas: (a) Um modelo de análise de crédito padrão que seja aplicável em todos os bancos, ou seja, não customizado a uma determinada instituição, pois, conforme a pesquisa realizada, cada banco possui suas idiossincrasias; (b) Treinamento e conhecimento de IFRS, CPC e legislação fiscal de todos os gestores de análise de crédito; (c) Treinamento e aperfeiçoamento continuado, a fim de acompanhar as atualizações em IFRS, CPC e legislação tributária; (d) Um processo que seja ágil e flexível; (e) Um modelo que não necessite de vultosos investimentos em infraestrutura e tecnologia da informação. 
A partir do modelo atual e com base nas premissas anteriores, por meio deste estudo, foi sugerida a adoção dessa nova proposta de modelo de análise de crédito composto por 13 fases, conforme a Figura 1. A fase de análise financeira é a principal mudança sugerida neste modelo de análise de crédito proposto.

É nessa fase que são apresentados e analisados os relatórios financeiros societários e relatórios fiscais, momento em que são observados aspectos de disparidades práticas e conceituais, sendo necessário o real entendimento da composição dessas diferenças.

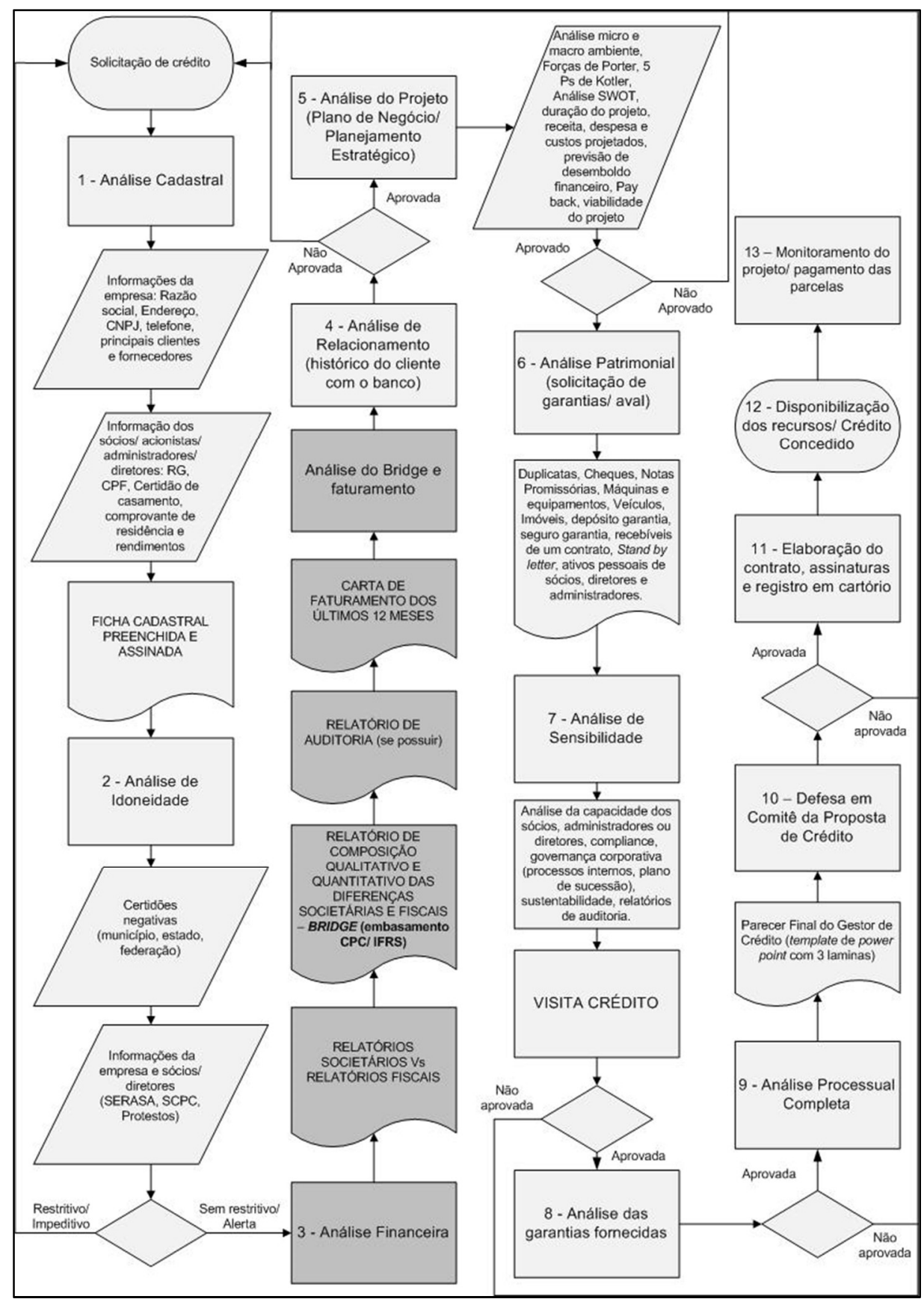

Figura 1: Fluxograma: modelo de crédito proposto.

Para o entendimento da composição dessas diferenças entre os relatórios societários e fiscais de acordo com as análises das categorias Contabilidade Fiscal (CAT 2) e Contabilidade Societária (CAT 3), vide Figura 2, foi sugerido a utilização de um relatório que mostre a composição dessas diferenças, o Bridge Report, que tem a finalidade de fazer o ajuste entre os relatórios societários e os fiscais. 
Outra sugestão, conforme análise da categoria Contabilidade Societária (CAT 3), é a seguinte: caso a empresa seja auditada, os relatórios de auditoria deverão ser aceitos desde que a empresa seja registrada no Instituto de Auditores Independentes do Brasil (IBRACON).

Também será analisada a carta de faturamento dos últimos 12 meses e a projeção do faturamento dos próximos 12 meses, a fim de verificar alguma sazonalidade no segmento e cruzar as informações com os relatórios societários e fiscais, visando eficiência na determinação da capacidade de pagamento.

De acordo com a categoria Risco (CAT 4), foi verificada a obrigatoriedade de garantias para suportar o risco do crédito concedido; por outro lado, também foi constatado nas categorias Contabilidade Fiscal (CAT 2) e Contabilidade Societária (CAT 3) que os processos de análise dos relatórios fiscais e societários poderiam ser aperfeiçoados.

As sugestões de melhorias têm a finalidade de mitigar o risco de inadimplência, deixando de tornar obrigatória a apresentação de garantias, proporcionando aos bancos uma maior flexibilidade na análise e solicitação de garantias aos clientes, caso ainda julguem necessário.

\begin{tabular}{|c|c|c|c|c|c|c|c|}
\hline & \multirow{2}{*}{$\begin{array}{l}\text { XXXXX Ltda } \\
\text { Moeda do relarório USD (000) } \\
\text { onstração de Resultado }\end{array}$} & \multicolumn{2}{|c|}{\begin{tabular}{|c|}
$\begin{array}{c}\text { Realizado Outubro } 2011 \text { - YTD } \\
\text { IFRS }\end{array}$ \\
\end{tabular}} & \multirow[t]{2}{*}{ BRIDGE } & \multicolumn{2}{|c|}{$\begin{array}{c}\text { Realizado Outubro } 2011 \text { - YTD } \\
\text { Relatório Fiscal } \\
\end{array}$} & \multirow[t]{2}{*}{ Justificativa } \\
\hline Demonstração de Resultado & & & & & & & \\
\hline 311 & RECEITA BRUTA & 10.400 .001 & & 5.660 .000 & 16.060 .001 & & \multirow{14}{*}{ 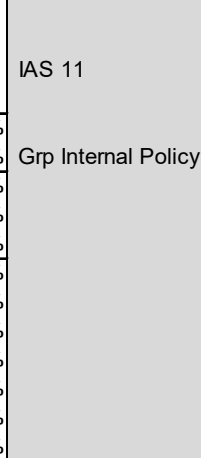 } \\
\hline 312 & DEDUÇÕES DE VENDAS & 861 & & & 861 & & \\
\hline 31 & RECETA LÍQUIDA & 10.399 .140 & $100,0 \%$ & & 16.060 .862 & $100,0 \%$ & \\
\hline 32 & CUSTOS DEMATERIAIS & 3.600 .000 & $34,6 \%$ & 1.560 & 3.601 .560 & $22,4 \%$ & \\
\hline 3CB1 & MARGEM DE CONTRIBUIÇÃO 1 & 6.799 .140 & $65,4 \%$ & & 12.459 .302 & $77,6 \%$ & \\
\hline 331 & MUDANÇAS DE ESTOQUES & - & $0,0 \%$ & & - & $0,0 \%$ & \\
\hline 332 & CUSTO DE MÃO DE OBRA & - & $0,0 \%$ & & - & $0,0 \%$ & \\
\hline 310 & RECETA DE OPERAÇÕES & 6.799 .140 & $65,4 \%$ & & 12.459 .302 & $77,6 \%$ & \\
\hline 34120 & SALÁRIOS E BENEFÍCIOS & 1.850 .768 & $17,8 \%$ & & 1.850 .768 & $11,5 \%$ & \\
\hline 34125 & BÔNUS & 28.765 & $0,3 \%$ & & 28.765 & $0,2 \%$ & \\
\hline 34130 & SEGUROS SOCIAIS & 628.080 & $6,0 \%$ & & 628.080 & $3,9 \%$ & \\
\hline 34133 & CUSTOS DE PREVID ENCIAS & - & $0,0 \%$ & & - & $0,0 \%$ & \\
\hline 34135 & OUTRAS DESPESAS PESSOAIS & 250.167 & $2,4 \%$ & & 250.167 & $1,6 \%$ & \\
\hline 34140 & DESPESAS DE TREINAMENTOS & - & $0,0 \%$ & & - & $0,0 \%$ & \\
\hline
\end{tabular}

Figura 2: Bridge Report.

Conforme foi verificado na categoria Contabilidade Societária (CAT 3), os profissionais de crédito não conhecem IFRS/ CPC, e, visando a correta análise do Bridge Report, foi sugerido o treinamento continuado dos profissionais de análise de crédito em IFRS/ CPC, e alinhamento dos procedimentos das Normas Internacionais com as Auditorias Internas dos bancos, uma vez que as normas estão em constante atualização. Tal treinamento e conhecimento também deverá ser disponibilizado aos auditores internos dos bancos para fins de alinhamento interno nas instituições financeiras.

Por fim, tendo sido uma pesquisa exploratória sobre o tema, alguns aspectos não foram considerados ou aprofundados, deixando a oportunidade para explorá-los em estudo futuros, tais como: (a) aumentar a base de dados por meio de um maior número de respondentes; (b) aprofundar as análises de empresas do segmento Middle Market, com o faturamento mais próximo ao segmento Corporate; (c) testar o modelo de crédito sugerido.

\section{REFERÊNCIAS}

ANTUNES, M. T. P.; GRECCO, M. C. P.; FORMIGONI, H.; MENDONÇA NETO, O. R.. A adoção no Brasil das normas internacionais de contabilidade IFRS: o processo e seus impactos na qualidade da informação contábil. Revista 
Economia \& Relações Internacionais, São Paulo, v.10, n.20, p.5-19, 2012.

BEUREN, I. M.; LONGARAY, A. A.; RAUPP, F. M.; SOUSA, M. A. B.; COLAUTO, R. D.; PORTON, R. A. B.. Como elaborar trabalhos monográficos em contabilidade. 3 ed. São Paulo: Atlas, 2009.

BLATT, Adriano. Crédito: Dicas práticas para analisar e conceder crédito. 3 ed. São Paulo: STS, 2000.

\section{BRASIL. Instrução Normativa no 21, de 13 de Março de} 1979. Brasília: DOU, 1970

BRASIL. CPC 17: Contratos em Construção. Brasília: DOU, 2014.

EUA. IAS 11. Construção de Contratos. 2014.

EUA. IAS 01. Presentation of Financial Statements. 2014.

CRESWELL, J. W. Qualitative Inquiry and Research Desigh: Choosing Among Five Traditions. Londres: Sage, 1998.

FORMIGONI, H.; ANTUNES, M. T. P.; PAULO, E.. Diferença entre o Lucro Contábil e Lucro Tributável: Uma Análise sobre o Gerenciamento de Resultados Contábeis e Gerenciamento Tributário nas Companhias Abertas Brasileiras. BBR, Vitória, v.6, n.1, p.44-61, 2009.

GALLO, M. F.. A relevância da abordagem contábil na mensuração da carga tributária nas empresas. Tese (Doutorado em Ciências Contábeis) - Universidade de São Paulo, São Paulo, 2007.
HOUAISS, A.. Grande Dicionário Houaiss da Língua Portuguesa. Instituto Antonio Houaiss, 2012.

IUDÍCIBUS, S.; MARTINS, E.; GELBCKE, E. R.; SANTOS, A. Manual de Contabilidade Societária. São Paulo: Atlas. 2010.

KIMURA, H.; PERERA, L. C. J.. Modelo de otimização da gestão de risco em empresas não financeiras. Revista Contabilidade e Finanças (USP), São Paulo, n.37, p.59-72, 2005.

PERERA, L. C. J.. Crédito: História, fundamentos e modelos de análise: Gerenciamento de Crédito. São Paulo: Saint Paul, 2013.

SANTOS, J. O.. Análise de crédito: empresas, pessoas físicas, agronegócio e pecuária. 3 ed. São Paulo: Atlas, 2009.

SECURATO, J. R.. Crédito: Análise e Avaliação do Risco: Pessoas Físicas e Jurídicas. São Paulo: Saint Paul, 2007.

SHIMKO, D.. Credit Risk Models and Management. Londres: Risk Books, 1999.

SILVA, J. P.. Gestão e análise de risco de crédito. 4. ed. São Paulo: Atlas, 2003.

SILVA, R. L. M.. Adoção completa das IFRS no Brasil: qualidade das demonstrações contábeis e o custo de capital próprio. Tese (Doutorado em Ciências) - Universidade de São Paulo, São Paulo, 2013. 